a living child, after a very favourable labour. She nursed her baby for some time, and now it is eight months old. A few weeks before admission she had an attack of diarrhoea, lasting some days. She had suffered from several attacks of acute pain in the belly at different periods of the past year, followed by much tenderness. As no gliding of the parietes on the cyst conld now be felt, adhesions were suspected as the result of the attacks of peritonitis. She had lost flesh lately, but ate well, and was in good spirits. Although fully aware of the danger of the operation, she had firmly made up her mind to have it done.

The patient was transferred to Mr. Curling, and, after a consultation with his colleagues, he determined to perform the operation. This was done on the 22 nd of March, 1861 , in a private ward, with the temperature at $75^{\circ}$, chloroform being given by Dr. Mackenzie. The integuments were divided to about four inches at first, and subsequently the incision was enlarged three inchos upwards, to just above the umbilicus. The cyst was now exposed, and found to be loosely adherent in front, but much stronger on both sides. As the contents of the cyst did not readily flow through the canula, the patient was partially turned on one side, and a free incision made into the front of it. No fluid was allowed to come into contact with the peritoneum. The adhesions to the omentum were very extensive, but not very firm; they were, however, in the right iliac and lumbar regions, where they were separated with some difficulty. The tumour involved the right, and not the left ovary, as was supposed by the patient. Its pedicle was long and thin, and was secured by a single piece of whipcord, the cyst being then cut away three inches higher up. The abdomen was now closed, and the wound united by hare-lip pins, the pedicle being brought ont and secured in position at the lowest part of the wound. After removal to bed, a suppository of ten grains of soap-and-opium pill was introciuced into the rectum. For a part of the time she went on well after the operation, especially the first twenty-four hours, being sedulously watched by Mr. Bush, the house-surgeon in charge. During the second night she suddenly became worse, but rallied under stimulants. Death, however, took place about sixty hours after the operation.

The autopsy showed extensive peritonitis of a low form. The peritoneal surfaces were everywhere greasy with soft lymph, which showed no tendency to organize. Some ounces of thick sanious fluid, but no coagula, occupied the pelvic fosse. The wound and the pedicle were in good condition; the former was well united, and the latter in process of separation. The cyst proved to be, as was previously supposed, unilocular; there were no secondary cysts whatever. Tapping had never been performed. Evidence was present of repeated and severe inflammation both within and without the cyst. The obstacle to the removal of the fluid by the trocar during the cperation consisted of a large floating false membrane, which had entangled itself on the end of the canula. It was of remarkable strength, and much resembled a piece of the omentum.

\section{POLYCYSTIC OVARIAN TUMOUR NOTICED SIX MONTHS;} OVARTOTOMY; RECOVERY.

(Under the care of Mr. MAUNDER.)

M. H_, aged twenty-two, has always enjoyed good health until within the last nine months, when she ceased to men. struate. About six months since she noticed a hard swelling on the right side of the abdomen, which has grown larger, and gradually extended towards the right side of this cavity. The patient came under Dr. Down's observation amongst the outpatients, when Mr. Maunder also saw her, and was of opinion, with Dr. Down, that the tumour was ovarian, and favourable for removal. Up to the moment of admission the patient had followed the occupation of a domestic servant.

Sept. 16th. The tumour was to-day removed by $\mathrm{Mr}$. Maunder, by a median incision below the umbilicus, made sufficiently large to admit the band to sweep the surface of the swelling. From twenty-five to thirty pints of semigelatinous fluid were evacuated from three principal cysts; after that, some slight adhesions to the anterior abdominal wall were torn through. The operator being ably aided by his colleagues, Mr. Hutchinson and Mr. Couper, no fluid found its way into the abdominal cavity, and a small knuckle of intestine was alone seen. The multilocular cyst having been withdrawn, the pedicle was tied by a double ligature, and by a second to encircle the whole, and was kept in position by a pin transfix. ing it behind the ligatures, as well as the edges of the wound. Sickness occurred during the operation, and persisted for some hours (being probably due to chloroform), and was followed by a troublesome pyrosis, lasting some days. The patient was fed per rectum for the first week, nothing but ice being allowed to pass the lips.

Oct. 29 th. - To-day she leaves the hospital, with the wound healed, except at its inferior angle, whence a little pus occasionally issues. Much credit was considered to be due to Mr. Woodman, the house-surgeon in charge, for the care and at. tention bestowed by him upon the patient during the after. treatment.

\section{GUY'S HOSPITAL.}

POLYCYSTIC OVARIAN TUAOUR, PREVIOUSLY TREATED BY TAPPING AND INJECTION OF IODINE; OVARIOTONY; DEATH IN TWENTY-SEVEN IIOURS.

(Under the care of Dr. HICEs and Mr. Brxant.)

Driferma from the other cases in the present series, the following had been treated by the injection of a watery solution of iodine on the occasion of a second tapping. The compound character of the disease, however, wholly precluded the possibility of any relief by this means, and ultimately the tumour was removed in the usual way. Although the patient's age was most favourable, yet the disease had severely told upon her constitutional powers; the result was consequently fatal, death ensuing in twenty-seven hours, from the coubined effects. of shock and peritonitis.

E. B-, aged twenty, married a year and a half. She first noticed the disease two months after marriage. She was ad. mitted into Mary ward, under the care of Dr. Hicks, in August, 1860 , and twelve quarts of fluid were evacuated by tapping. A sinall secondary cyst was at that time noticeable in the anterior part of the right side of the cyst-wall. In November of the same year she was again admitted, tapped, and the cyst injected with a watery solution of iodine. Much irritation was caused by the operation, but she went out in about a month. The secondary cysts were found, on this second tapping, much increased in size, number, and solidity. She was a third time admitted in May, 186l. The secondary growths had now formed a hard mass, which had enormously increased, at the expense of the primary, and, when tapped, only yielded a few pints of pale, flaky thuid. The rest of the cysts were small, and it was found of no use to puncture them. She went out in a fortnight; but her health beginning to fail, and the last tapping not having afforded much relief, the only chance for cure which remained was by excision. On her re-admission, this operation was proposed and accepted. She had become decidedly thinner since her first admission.

Chloroform having been administered, the operation was performed on July 9 th. Owing to the warmth of the weather, no necessity existed for any precautions concerning temperature, except to obtain fresh air. A good-sized room in the centre of the hospital was chosen. The small incision was made, extending from over an inch below the umbilicus to an inch above the pubes-about four inches altogether. A remarkably thin cyst was observed, which was tapped. Several secondary cysts appeared, and on attempting to withdraw them from the abdomen they tore easily, and discharged their contents into the peritoneum. They appeared to be composed of the thinnest membrane, and broke down on the slightest touch. The greater part of the cysts were non-adherent to the parietes of the abdomen, but some were attached, and a considerable surface of omentum was firmly adherent to them. This was carefully separated. A very small pedicle appeared on the left side, which was attempted to be secured by a wire suture, twisted with a pair of carpenters' nippers. This not being considered by Mr. Forster sufficiently secure, the pedicle was tied with a ligature; the contents of the cysts, with the blood which had passed into the peritoneum, were then carefully removed; and as considerable oozing was still taking place from the omentum, it was tied. The ligatures around the omentum and pedicle were returned into the abdomen, and the lips of the incision in the parietes were brought together by pins. The patient never rallied, and died in twenty-seven hours.

Pcst-mortem examination. - Slight general peritonitis of a low form was observed; the coils of intestine were united together, and the pelvis contained a pint of pink-coloured turbid fluid, but no coagulum; the ligature was round the omentum, and the operation appeared to have been perfect. The uterus with its right ovary and tube were healthy and free; the ligature was around the pedicle of the left. The anterior walls of the ab. domen were covered in places with shreds of tissue, from the tearing away of the cyst. 